\title{
ERRATUM
}

\section{Chapter 3 \\ Modulation of C-nociceptive Activities by Inputs from Myelinated Fibers}

\author{
Wan-Ru Duan and Yi-Kuan Xie \\ (c) Springer Science+Business Media Dordrecht 2016 \\ C. Ma, Y. Huang (eds.), Translational Research in Pain and Itch, Advances \\ in Experimental Medicine and Biology 904, DOI 10.1007/978-94-017-7537-3
}

DOI 10.1007/978-94-017-7537-3_11

The original version of this chapter unfortunately contained a mistake. In Chap. 3 titled "Modulation of C-nociceptive Activities by Inputs from Myelinated Fibers", the family name and given name of the authors were reversed as Duan Wan-Ru and Xie Yi-Kuan. Hence the correct name should read as below.

Wan-Ru Duan and Yi-Kuan Xie. 